\title{
Evaluation of blood reservation and use for caesarean sections in a tertiary maternity unit in south western Nigeria
}

\author{
Oluwarotimi I Akinola*, Adetokunbo O Fabamwo, Adetokunbo O Tayo, Kabiru A Rabiu, Yussuf A Oshodi, \\ Chioma A Onyekwere
}

\begin{abstract}
Background: Haemorrhage from obstetric causes is the most common cause of maternal mortality in the developing world. Prevention of mortality from haemorrhage will necessarily involve prompt blood transfusions among other life saving measures. There are however limited stocks of fresh or stored blood in many health care facilities in Sub Saharan Africa. Caesarean section has been identified as a common indication for blood transfusion in obstetrics practice and its performance is often delayed by non availability of blood in our centre. An evaluation of blood reservation and use at caesarean sections in a tertiary maternity unit in Lagos, south western Nigeria should therefore assist in formulating the most rational blood transfusion policies.

Methods: Case records of 327 patients who had elective and emergency caesarian sections at the Lagos State University Teaching Hospital between $1^{\text {st }}$ October and $31^{\text {st }}$ December 2007 were reviewed. Data pertaining to age, parity, booking status, type and indication for Caesarean section, pre- and post-operative packed cell volume, blood loss at surgery, units of blood reserved in the blood bank, unit(s) of blood transfused and duration of hospital stay was extracted and the data analysed.
\end{abstract}

Results: There were 1056 deliveries out of which 327 (31\%) were by Caesarean section. During the study period, a total of 654 units of blood were reserved in the blood bank and subsequently made available in theatre. Out of this number, only $89(13.6 \%)$ were transfused to 41 patients. Amongst those transfused, twenty-six (54\%) were booked and 31 (75.6\%) had primary caesarian section. About $81 \%$ of those transfused had emergency caesarean section. The most common indication for surgery among those transfused were placenta praevia ( 9 patients with 21 units of blood) and cephalo-pelvic disproportion (8 patients with 13 units).

Conclusion: Even though a large number of units of blood was reserved and made available in the theatre at the time of operation, majority of the patients operated did not need blood transfusion. Provision of a mini- blood bank within the obstetric unit and careful patient categorization will ensure timely availability of blood for surgery without necessarily tying down stock in the central blood bank.

\section{Background}

Peripartal haemorrhage is still the leading cause of maternal and fetal morbidity and mortality in developing countries [1]. Despite advances in the prevention, diagnosis and treatment, massive blood loss during pregnancy and delivery remains a threat and therefore, prevention of maternal mortality involves prompt blood

\footnotetext{
* Correspondence: iretiakinola@hotmail.com

Department of Obstetrics and Gynaecology, Lagos State University Teaching Hospital, Ikeja, Lagos State, Nigeria
}

(c) 2010 Akinola et al; licensee BioMed Central Ltd. This is an Open Access article distributed under the terms of the Creative Commons Attribution License (http://creativecommons.org/licenses/by/2.0), which permits unrestricted use, distribution, and reproduction in any medium, provided the original work is properly cited. the fifth millennium development goal [2].

Caesarian delivery is often performed in young patients who are free of serious cardiovascular and pulmonary diseases. The procedure has been identified as a common indication for blood transfusion in obstetric practice because it involves risk of major intra-operative blood loss [3]. Its performance is often delayed by non-availability of blood $[4,5]$. The increased blood volume associated with normal pregnancy typically accommodates 
the obligatory blood loss that occurs during vaginal or caesarian delivery [6]. However, in some patients, blood loss may overwhelm compensatory mechanisms and result in hypovolaemia and shock with a significant threat to both the mother and fetus [7]. Transfusion practices have changed during the last two decades because of acute awareness of the increased risks associated with blood transfusion as well as an improved knowledge of the patho-physiologic mechanism of oxygen transport and tissue oxygenation [3].

In our centre, anaesthetists usually request for a minimum of two units of cross-matched blood for cases of caesarean section irrespective of the pre-operative haematocrit. Most of these cross-matched pints of blood are seldom used. The blood gets tied down and is unavailable for other users. Unnecessary blood reservation, apart from the consideration of cost, may result in apparent blood scarcity especially in facilities where blood is in short supply. This then denies those patients who really need blood for life saving interventions [8].

There is evidence to suggest that the attitude to blood preservation and use is fairly similar in this subregion [8]. The need to focus on preserving the blood supply, increasing availability, ensuring rational reservation and use, enhancing its safety and decreasing cost without compromising the quality of care informs the necessity for this study. We therefore undertook an audit of blood reservation and transfusion practices for caesarean section at this centre with a view to recommending modifications wherever it is found to be suboptimal.

\section{Methods}

This was a retrospective descriptive study conducted between $1^{\text {st }}$ October and $31^{\text {st }}$ December 2007 in the Obstetrics and Gynaecology Department of the Lagos State University Teaching Hospital (LASUTH), Ikeja. The study protocol was approved by the Research and Ethics Committee of the institution.

Case records of patients who had caesarean delivery during the period were reviewed. Data were obtained on age, parity, booking status, type of and indication for caesarian section, blood loss at surgery and duration of hospital stay. Other information extracted include pre and post operative haematocrit, units of blood reserved at the blood bank and units of blood actually transfused. Booked cases were those that registered and were receiving antenatal care in the department of Obstetrics and Gynaecology, LASUTH, while unbooked cases were those that were brought in as emergency outside LASUTH even though they might have received antenatal care elsewhere.

Surgery was performed by experienced residents and consultants according to standardized protocol [9] and placenta were delivered by controlled cord traction except where this was difficult and manual removal performed. Blood loss was estimated by counting the number of soaked abdominal packs, gauzes, measurement of blood volume in the vagina after caesarean section and visual estimation of blood staining of the theatre bedspread.

Data obtained were analyzed with SPSS version XIV (Chicago Illinois). Variables were summarized using frequency, mean and standard deviation. The Chi-square test and Student's t-test were used to test for associations between variables as appropriate. $P$ value of less than 0.05 was considered statistically significant, confidence level was set at $95 \%$.

\section{Results}

Three hundred and twenty seven patients had caesarean delivery amongst 1056 parturients during the study period giving a caesarian section rate of $40 \%$. Six hundred and fifty four units of blood were cross-matched for the procedure but only 89 units (13.6\%) were transfused giving cross-matched: transfusion ratio of 7.4:1.

Forty-one (12.5\%) of those that had Caesarean section were transfused. Table 1 shows the characteristics of the patients. Two-hundred and twenty-one (67.5\%) patients were booked, out of whom $26(11.7 \%)$ were transfused whereas 15 (14.2\%) among the 106 unbooked patients were transfused.

Elective caesarian section was performed on 82 patients out of whom 8 (9.8\%) were transfused compared to $33(13.5 \%)$ that were transfused among those that had emergency caesarian section $(\mathrm{P}<0.05)$. Two hundred and thirty-two patients had primary caesarean section out of whom 33 were transfused (14.2\%) compared to only $8(8.4 \%)$ that were transfused among the 95 patients who had repeat caesarian section.

Table 2 depicts indications for caesarean section with reference to the frequency and blood transfusion

\section{Table 1 Characteristics of patients that had caesarian section and blood use}

\begin{tabular}{lllll}
\hline Parameters & Total C/S & No. transfused & Units & \\
\hline Booking status & & & & \\
Booked & $221(67.5 \%)$ & $26(11.7 \%)$ & $54(61 \%)$ & $P=0.09$ \\
Unbooked & $106(32.5 \%)$ & $15(14.2 \%)$ & $35(39 \%)$ &
\end{tabular}

Type of $\mathrm{C} / \mathrm{S}$

Elective $\quad 82(25 \%) \quad 8(9.8 \%) \quad 19(21 \%) \quad \mathrm{P}<0.05$

Emergency $\quad 245(75 \%) \quad 33(13.5 \%) \quad 70(79 \%)$

Primary C/S $\quad 232(71 \%) \quad 33(14.2 \%) \quad 72(81 \%) \quad P<0.05$

Repeat C/S $95(29 \%) \quad 8(8.4 \%) \quad 17(19 \%)$

$\begin{array}{llll}\text { Total } & 327 & 41 & 89\end{array}$


Table 2 Indications for caesarean section and number transfused

\begin{tabular}{lccc}
\hline Indication & Frequency & No. transfused & Units received \\
\hline CPD* $^{*}$ & 61 & 6 & $9(10.1 \%)$ \\
Previous Scar & 52 & 7 & $16(18 \%)$ \\
Fetal distress & 34 & 3 & $5(5.6 \%)$ \\
Placenta praevia & 22 & 9 & $21(23.6 \%)$ \\
Breech & 20 & 1 & $1(1.1 \%)$ \\
Pre-eclampsia/eclampsia & 19 & 2 & $4(4.5 \%)$ \\
PL $^{*}$ /Obst\#\#. Labour & 17 & 3 & $7(7.9 \%)$ \\
Failed Induction $^{\text {BOH** }}$ & 12 & 1 & $1(1.1 \%)$ \\
Abnormal CTG & 9 & - & - \\
Malpositioning & 9 & - & - \\
Multiple pregnancy & 8 & 1 & $1(1.1 \%)$ \\
Cervical dystocia & 8 & 2 & $5(5.6 \%)$ \\
PMTCT & 8 & - & - \\
Malpresentation & 8 & 1 & $4(4.5 \%)$ \\
HbSS*** $_{\text {Abruptio placenta }}$ & 5 & 1 & $1(1.1 \%)$ \\
Others & 3 & 2 & $7(7.9 \%)$ \\
\hline & 3 & 2 & $7(7.9 \%)$ \\
\hline
\end{tabular}

* Cehalopelvic disproportion * Prolonged labour

** Bad obstetrics history ${ }^{\# \# ~ O b s t r u c t e d ~ l a b o u r ~}$

+ Prevention of mother to child transmission *** Sickle cell anaemia

practice. Indication for surgery among those transfused were placenta praevia (9 patients) who had 21 units of blood, Cephalo-pelvic disproportion (8 patients) with 13 units, previous caesarian section (4 patients) with 10 units, Sickle cell disease Hb SS (3 patients) with 7 units while eclampsia and fetal distress accounted for 2 patients who had transfusion with 4 and 3 units respectively.

Table 3 compares some parameters between transfused and non-transfused patients. There was no statistically significant difference between their mean age (30.2 \pm 5.18 years $)$ and $(30.4 \pm 4.93)$. Similarly, there was no significant difference in the parity of those transfused (range 0-4, median 1) and non-transfused (range 0-4, median 1). However, estimated blood loss (EBL) at

Table 3 Comparison between those transfused and nontransfused $\mathbf{C} / \mathrm{S}$

\begin{tabular}{llllll}
\hline Parameter & \multicolumn{2}{l}{ Non-transfused } & \multicolumn{2}{l}{ Transfused } & P value \\
& Mean & (S/D) & Mean & (S/D) & \\
\hline Age & 30.4 & $(4.9)$ & 30.2 & $(5.2)$ & $\mathrm{P}=0.17$ \\
Parity & 1.02 & $(1.1)$ & 1.07 & $(0.9)$ & $\mathrm{P}=0.13$ \\
Blood loss & 537.5 & $(294.2)$ & 848.3 & $(736.2)$ & $\mathrm{P}<0.01$ \\
Pre-op PCV & 33.6 & $(5.3)$ & 27.2 & $(6.1)$ & $\mathrm{P}<0.01$ \\
Post-op PCV & 31.1 & $(5.1)$ & 26.6 & $(5.7)$ & $\mathrm{P}<0.001$ \\
Hospital stay & 8.3 & $(3.3)$ & 10 & $(4.0)$ & $\mathrm{P}=0.06$ \\
Units transfused & & - & 2.2 & $(1)$ & \\
\hline
\end{tabular}

Table 4 Pattern of transfusion and frequency of usage

\begin{tabular}{lll}
\hline Unit of blood & No. of patients (\%) & Units transfused \\
\hline 1 & $7(17.0 \%)$ & 7 \\
2 & $25(60.9 \%)$ & 50 \\
3 & $5(12.2 \%)$ & 15 \\
4 & $3(7.3 \%)$ & 12 \\
5 & $1(2.5)$ & 5 \\
\hline Total & $41(100 \%)$ & 89 \\
\hline
\end{tabular}

surgery, pre-operative and post- operative haematocrit demonstrated statistically significant differences between the two groups. The mean EBL for the transfused subjects was $848.3 \pm 736.2 \mathrm{ml}$ compared to $537.5 \pm 294.2$ $\mathrm{ml}$ in the non-transfused subjects $(\mathrm{P}<001)$. The mean pre-operative haematocrit in those transfused was $27.2 \pm$ 6.1 percent compared to $33.6 \pm 5.3$ percent obtained in the non-transfused subjects $(P<001)$. Similarly, the mean post-operative haematocrit in those transfused was $26.6 \pm 5.7$ percent compared to $31.1 \pm 5.1$ percent obtained in the non-transfused subjects $(\mathrm{P}<001)$.

Table 4 depicts the unit(s) of blood transfused and the frequency. It was observed that seven patients had one unit transfusion (17\%), 25 patients were transfused with two units of blood (61\%) and 5 had three units of blood transfusion (12.2\%). Others include 3 patients that had four units of blood (7.3\%) and one who had five units of blood transfused (2.5\%).

\section{Discussion}

The increasing use of surgery for childbirth and subsequent need for blood transfusion together with patient's reluctance to receive homologous transfusion poses a challenge to the obstetricians and anaesthetists [10]. Although, improvement in obstetrics surgical techniques and practice may have decreased the use of homologous blood transfusion at the time of caesarean section, the risk of requiring blood transfusion is still significant especially in high risk cases [11]. Certain trends or consideration have contributed to decreasing transfusion rate. These include physician's acceptance of lower perioperative haemoglobin concentration or haematocrit levels, reduced patient's willingness to accept the risk of transmission of blood borne infectious agents, more restrictive indications for blood transfusion and the fact that the obstetrics population is largely young and healthy [12].

The caesarean section rate in this study was $40 \%$ which is very high compared to $10-15 \%$ in the United States[13] and 5-21.8\% reported in Sub-saharan Africa [14]. However, the World Health Organization suggested a caesarian section rate of $5-15 \%$ in any facility [15]. This high incidence has been an issue of international health concern although most cases in this study 
were emergencies with genuine indications. Our facility also serves as one of 3 tertiary referral centres for Lagos metropolis with a population of about 15 million inhabitants.

The transfusion rate among the patients that had caesarean delivery was $12.5 \%$. This is consistent with transfusion rate of $1-14 \%$ as suggested by review of literature for blood transfusion following caesarean section [11]. The blood transfusion rate in this study is higher than $4.9 \%$ and $5.4 \%$ reported by Duthie et al [16] and Rouse et al [17] but significantly lower than $23.5 \%$ and $25.2 \%$ reported by Rainaldi et al [10] and Ozumba et al [18].

Considering the demographic characteristic of patients who had blood transfusion and those who did not, the age, parity and booking status were not significantly associated with increased risk of blood transfusion. This is contrary to the findings of Imarengiaye et al [19] who reported a six fold risk of blood transfusion in unbooked cases and might be a reflection of some degree of antenatal care even in the 'unbooked' patients in a cosmopolitan setting as ours. However, emergency caesarean section was found to increase the risk of transfusion as $13.5 \%$ of patients in this category were transfused compared to $9.8 \%$ of those that had elective surgery. This finding is consistent with the report by Tolby and Scott [20] who found a statistically significant risk of transfusion in their subjects undergoing emergency caesarean section.

Of the 232 subjects that had primary caesarean section, $14.2 \%$ of them were transfused compared to $8.4 \%$ of the 95 subjects that had repeat surgery. This was found to be statistically significant $(\mathrm{P}<0.05)$. Our finding is in contrast with that of Imarengiaye [19] who found significant risk of transfusion with repeat caesarean section. However, this increased rate of transfusion with primary surgery in our study may be because of a preponderance of cases related to prolonged labour secondary to cephalo-pelvic disproportion. In these cases, there is usually post-operative uterine atony due to muscle fatigue in addition to low pre-operative haematocrit among the unbooked emergencies. As noted in this study, cephalo-pelvic disproportion was found to be the most common indication for emergency caesarian section in most series [18,21]

The highest transfusion rate was seen in cases of placenta praevia with 9 patients receiving a total of 21 units of blood transfusion. This accounts for $41 \%$ of total patients with placenta praevia as the indication for surgery compared to $59.1 \%$ similar subjects transfused in the Ozumba study [18]. Pregnancies complicated by placenta praevia are noted for increased blood loss and transfusion at surgery. Factors responsible include repeated ante-partum haemorrhage which may lower the haematocrit, thus putting the patient at a point close to transfusion trigger. Similarly, the low-lying placenta may provoke increased and uncontrollable intraoperative haemorrhage necessitating blood transfusion [19]. Other indications for caesarian section with associated risk of transfusion in this study include previous uterine scar, prevention of mother to child transmission of human immune deficiency virus, obstructed labour, multiple pregnancy, abruptio placenta, haemoglobinopathy and pre-eclampsia/eclampsia. Most of these factors have been corroborated by other authors [17-19,22,23].

The estimated blood loss at surgery in this study was significantly associated with increased risk of blood transfusion. The mean EBL among patients transfused was $848.3 \pm 736.2 \mathrm{mls}$ compared to $537.5 \pm 294.2 \mathrm{mls}$ in the non-transfused patients $(\mathrm{P}<0.01)$. The corresponding EBL values reported by Imarengiaye et al [19] was $1310.8 \pm 991.8 \mathrm{mls}$ and $592.5 \pm 181.7(\mathrm{P}=0.001)$ for transfused and non-transfused subjects respectively. Others authors also found strong association between intra-operative blood loss and risk of blood transfusion at caesarian section $[3,11,17-19]$. The role of anaemia as represented by pre- and post-operative haematocrit level was also found to be significantly associated with increased transfusion risk in this study $(\mathrm{P}<0.01)$. This association was reported in other works [17-19]. Though a transfusion haematocrit threshold of $30 \%$ or less has been suggested as appropriate [24], the mean pre-transfusion haematocrit in this study was $27.2 \%$. While women who underwent caesarian section may tolerate post-operative haematocrit of $20 \%$ without significant complications, transfusion with red blood cells may be appropriate when the haematocrit is $21-30 \%$ if there is active bleeding or cardio-pulmonary disturbance [25].

The breakdown of units of blood transfused revealed that 7 (17\%) of the subjects received one unit of blood. This is slightly higher than $13.3 \%$ reported by Imarengiaye et al [19] but significantly lower than $43.1 \%$ and $68.2 \%$ of one unit transfusion reported by Ozumba et al [18] and Khan et al [23]. The latter authors opined that those transfusions were unnecessary and the patients could have survived with plasma expanders instead of one unit of blood transfusion with its attendant risks and complications.

Moreover, several professional societies suggested that the decision to transfuse a specific patient should take into consideration many factors other than specific haemoglobin concentration [26-29]. While the American College of Physicians suggested that even in a symptomatic patient, one unit transfusion may be sufficient, recent guidelines by the British Committee for standard in haematology recommended that if otherwise stable, two units of red cells should be transfused [27-29]. However, the goal of transfusion can be achieved in certain instances with a single unit of blood transfusion 
with an interim assessment to determine the need for second unit. Therefore, the need for the well established practice of two unit transfusion regardless of the level of anaemia is questionable.

The short duration of this study and its cross sectional nature are significant limitations as it might not reflect long term practice and trends and certainly could not assess the long term effect of blood transfusion policy on subsequent health of the subjects [30]

Since only 89 of all 654 units cross-matched blood was used, this gave a cross match transfusion ratio of 7.4:1. It also indicated that only $12.5 \%$ of cross-matched blood was used. The cross-match transfusion ratio is a method of evaluating the efficiency of blood bank ordering practice [17]. The cost of cross-matching a unit of blood in our facility is three thousand naira $(\# 3000: 00=20$ USD) and the cost of cross-matching for the unused 565 units of blood is \#1,695,000 (11,300 USD). This amount represents a large wasteful financial expenditure and possibly waste products if the blood was not returned on time before denaturation sets in. Current literature advocates type and screen as a safe alternative to pre-operative type and cross-match for procedures requiring less than one unit per case [31]. Advocates of pre-operative type and screen policy for obstetric procedures claimed substantial savings as a result, suggesting that this policy could substantially reduce cost without harm to the patient. This policy change includes defining criteria for cross-matching patients with high risk for bleeding as listed earlier from identified risk factors for transfusion.

However, if the clinical circumstances of a low risk patient who initially had a hold clot order changes putting the patient at high risk, the blood bank is notified immediately. With this approach, delay in rendering care regarding transfusion need not arise as blood group $\mathrm{O}$ rhesus negative cross-matched blood could be given in the interim pending the availability of fully crossmatched blood.

It is desirable to revisit the blood banking order with respect to rational blood use and reservation for caesarian section. In the absence of significant risk factors for haemorrhage, routine pre-operative type and crossmatch does not enhance patient's care, substantially increase cost and should be eliminated [32]. However, hold clot order for low risk patients, availability of blood group $\mathrm{O}$ rhesus negative cross-matched blood in a miniblood bank attached to the obstetrics unit and careful categorization with cross-matched blood for high risks are viable alternatives that reduce cost and make utilization of scarce resources efficient.

\section{Conclusion}

This study has shown that even though a large number of units of blood was reserved and made available in the theatre at the time of caesarean section, majority of the patients operated did not need blood transfusion, resulting in a large cross-match transfusion ratio and consequently a large waste of financial, laboratory and blood bank resources. In developing countries with limited availability of blood and blood products, provision of a mini-blood bank within the obstetric unit and careful patient categorization may probably ensure timely availability of blood for surgery without necessarily tying down stock in the central blood bank.

\section{Acknowledgements}

The authors wish to acknowledge the contribution of Mr A S Opawale, who assisted with the statistical analysis of the data.

\section{Authors' contributions}

OIA conceived the study and participated in its design and co-ordinated the data collection, analysis and wrote the first draft of the paper. AOF, AOT, KAR, YAO and CAO participated in the study design, data collection, analysis and helped to draft the manuscript. All authors read and approved the final manuscript.

\section{Competing interests}

The authors declare that they have no competing interests.

Received: 2 June 2010 Accepted: 23 September 2010 Published: 23 September 2010

\section{References}

1. Gombowtz H: Blood sparing in obstetrics emergencies. [http://www. hdubl.hr/Predavanja/Gombowtz\%20Hans.doc].

2. United Nations Development Program: Millenium Development Goals. Goal 5 Improving maternal Health. [http://www.undp.org/mdg/goal5. shtml].

3. Matot I, Einav S, Goodman S, Zeldin A, Weissman C, Elchalal U: A survey of physician's attitude towards blood transfusion in patients undergoing caesarean section. Am J Obstet Gynecol 2004, 190:462-7.

4. Orji EO, Ojofeintimi EO, Esimai AO, Adejuyigbe E, Adeyemi AB, Owolabi OO: Assessment of delays in receiving delivery care at a tertiary healthcare delivery centre in Nigeria. Journal of Obstetrics and Gynaecology 2006, 26(7):643-644

5. Onah HE, Ibeziako N, Umezulike AC, Effetie ER, Ogbuokiri CM: Decisiondelivery interval and perinatal outcome in emergency caesarean sections. Journal of Obstetrics and Gynaecology 2005, 25(4):342-346.

6. Waterstone M, Wolfe C, Hooper R, Bewley S: Postnatal morbidity after childbirth and severe obstetric morbidity. Br J Obstet Gynaecol 2003, 110:728-33.

7. Häger RM, Daltveit AK, Hofoss D, Nilsen ST, Kolaas T, Øian P, Henriksen T: Complications of caesarian deliveries: rates and risk factors. Am J Obstet Gynecol 2004, 190:428-34.

8. Anorlu RI, Orakwe CO, Abudu OO, Akanmu AS: Use and misuse of blood transfusion in Obstetrics in Lagos, Nigeria. W Afr J Med 2003, 22:124-127.

9. Simm A, Ramoutar P: Caesarian section: technique and complications. Curr Obstet Gynaecol 2005, 15:80-86.

10. Rainaldi MP, Tazzari PL, Scagliarini G, Borghi B, Conte R: Blood salvage during caesarean section. Br J Anaesth 1998, 80:195-8.

11. Rebarber A, Lonser R, Jackson S, Copel JA, Sipes S: The safety of intraoperative autologous blood collection and auto transfusion during caesarean section. Am J Obstet Gynecol 1998, 179:715-20.

12. Carmann WR, Datta S: Red cell use during caesarean delivery. Transfusion 1991, 31:12-15.

13. Ventura SJ, Martins JA, Curtin SC, Matthews TJ, Park MM: Births: Final data for 1998. National vital statistics report; volume 48, number 3 Hyattsville, MD: National Centre for Health and Statistics 2000.

14. Shah A, Fawole B, M'Imunya MJ, Amokrane F, Nafiu I, Wolomby JJ, Mugerwa K, Neves I, Nguti R, Kublickas M, Mathai M: Caesarean delivery outcomes from the World Health Organisation global survey on 
maternal and perinatal health in Africa. Int'l J Obstet Gynaecol 2009, 107:191-197.

15. Chalmers B, Mangiaterra V, Porter R: World Health Organisation principles of perinatal care: the essential antenatal, perinatal and postpartum care course. Birth 2001, 28:202-7.

16. Duthie SJ, Ghosh A, Ng A, Ho PC: Intra-operative blood loss during elective lower segment caesarian section. Br J Obstet Gynaecol 1992, 99:364-367.

17. Rouse DJ, MacPherson C, Landom M, Varver MW, Levono KJ, Moawad AH, Spong CY, Cavitis SN, Meis PJ, Wapner RJ, Sorokin Y, Miodornik M, Carpenter M, Peacemen AM, O'Sullivan MJ, Sibai BM, Langer O, Thorp Jm, Ramin SM, Mercer BM: Blood transfusion and caesarian delivery. Br J Anaesth 1998, 80:195-8.

18. Ozumba BC, Ezegwui HU: Blood transfusion and caesarean section in a developing country. J Obstet Gynaecol 2006, 26:746-748.

19. Imarengiaye CO, Ande ABA: Risk factors for blood transfusion during caesarian section in a tertiary hospital in Nigeria. Med Sci Monit 2006, 12: CR269-272.

20. Tolby M, Scott DB: Blood loss during caesarean section under general anaesthesia. Br J Anaesth 1969, 41:868-73.

21. Swende TZ, Faagee TN: Caesarean morbidity in a Northern Nigeria tertiary health centre. Jos Journal of Medicine 2008, 3:23-25.

22. Imberti R, Preseglio I, Trotta V, Filisetti P, Mapelli A: Blood transfusion during caesarean section: A 12 years' retrospective analysis. Acta Anaesthesiol Belg 1990, 41(2):139-144.

23. Khan FA, Khan M, Ali A, Chohan U: Estimation of blood Loss during caesarean section: an audit. Journal of Pakistan Medical Association 2006, 56:572-575.

24. Inglis S, Lidon-Rice I, Yun H, Chervenal FA: Is observation of severe acute anaemia in women safe? Am J Obstet Gynecol 1995, 172:290.

25. American College of Obstetricians and Gynaecologists: Blood component therapy. ACOG technical bulletin No 199, Washington DC: American College of Obstetricians and Gynaecologists 1994.

26. American Society of Anaesthesiologists Task Force on Blood Component Therapy: Practice guidelines for blood component therapy. Anaesthesiology 1996, 84:732-747.

27. American College of Physician: Practice strategies for elective red blood cells transfusion. Ann Intern Med 1992, 116:403-406.

28. National Institute for Health: Consensus Conference. Perioperative red blood cell transfusion. JAMA 1988, 26:2700-3.

29. British Committee for Standards in Haematology, Blood Transfusion Task Force: Guidelines for the clinical use of red cell transfusion. $\mathrm{Br} J$ Haematol 2001, 113:24-31.

30. Inoue $Y$, Wada $Y$, Motobashi $Y$, Koizumi A: History of blood transfusion before 1990 is associated with increased risk for cancer mortality independently of liver disease: a prospective long-term follow-up study. Environmental Health and Preventive Medicine 2010, 15(3):180-187.

31. Cousin LM, Teplick FB, Poeltler DM: Pre-caesarian blood bank orders: A safe and less expensive approach. Obstet Gynaecol 1996, 87:912-916.

32. Ransom SB, Fundaro G, Dombrowski MP: Cost effectiveness of routine blood type and screen testing for caesarian section. J Reprod Med 1999, 44:592-4.

Pre-publication history

The pre-publication history for this paper can be accessed here: http://www.biomedcentral.com/1471-2393/10/57/prepub

doi:10.1186/1471-2393-10-57

Cite this article as: Akinola et al: Evaluation of blood reservation and use for caesarean sections in a tertiary maternity unit in south western Nigeria. BMC Pregnancy and Childbirth 2010 10:57.

\section{Submit your next manuscript to BioMed Central and take full advantage of:}

- Convenient online submission

- Thorough peer review

- No space constraints or color figure charges

- Immediate publication on acceptance

- Inclusion in PubMed, CAS, Scopus and Google Scholar

- Research which is freely available for redistribution

Submit your manuscript at www.biomedcentral.com/submit
Biomed Central 